\title{
GROOMING BEHAVIOR IN DIPLURA (INSECTA: APTERYGOTA)
}

\author{
By Barry D. Valentine and Michael J. Glorioso \\ Departments of Zoology \& Entomology respectively, \\ The Ohio State University, Columbus, Ohio 43210
}

Insect grooming studies are adding an important new dimension to knowledge of comparative behavior and evolution. Recent advances include an overview of a few selected movements of insects and myriopods (Jander, 1966), studies of the functional morphology of grooming structures (Hlavac, 1975), extensive reports about individual orders (Coleoptera: Valentine, 1973; Hymenoptera: Farish, 1972), quantitative studies at species levels (Chironomidae: Stoffer, in preparation; Drosophila: Lipps, 1973), and many less inclusive works. All such studies have difficulties which include the inability to know when an observed sequence is complete, the enormous number of potential taxa, the problem of generalizing about families and orders from small samples of individuals or species, and the absence of data from primitive or odd groups which may be critical for interpreting evolutionary sequences. The first three difficulties can be partially solved by increasing sample sizes and combining observations; however, the fourth can be solved only by availability. Grooming in the apterygote order Diplura is a good example because we can find only incomplete reports on one species. Recently, we have studied ten live specimens representing two families and three species; the data obtained provide an important picture of grooming behavior in one of the most primitive surviving orders of insects. Our observations greatly extend the limited discussion of grooming in the European japygid Dipljapyx humberti (Grassi, 1886) reported by Pagés $(1951,1967)$. Data on Dipljapyx are incorporated here, but have not been verified by us.

Initially we asked two questions: The first concerned whether a very primitive insect would enable us to observe a primitive grooming repertory; what we actually observed were primitive insects with grooming behavior beautifully tuned to a special and restricted environment. The second question concerned the effects

*Manuscript received by the editor September 26, 1978. 
of endognathous mouthparts on grooming. The invaginated, noncondylar mandibles and maxillae of Diplura might reduce their effectiveness in oral cleaning, and result in an increased importance of leg rubbing movements. In fact, leg rubbing was seldom observed. The rarity of rubbing has two possible explanations: either endognathy does not significantly modify grooming or else most leg rubbing movements have not yet evolved in Diplura.

\section{MATERIAL EXAMINED}

Campodeidae (seven specimens and seven hours of recorded observations plus about five additional hours of non recorded observation which add no new data) Ohio, Franklin Co., Columbus, Upper Arlington, 20 September, 1975, B. D. Valentine family, in soil in back yard (1 specimen). Same data except 5 November, 1977, in soil under boards and logs in back yard (6 specimens). Many additional specimens were seen and collected by breaking up clods of dirt in a garden.

Japygidae (three specimens and nine hours of recorded observation plus about four more hours which duplicate previous data). Alabama, Butler Co., 2 mi. N.W. McKenzie on U.S. rte. 31, 7 December, 1975, B. D. Valentine, R. L. Stoffer, A. J. Penniman, in rich humus under leaf litter (1 specimen). Ohio, Franklin Co., Columbus, 23 October, 1977, M. J. Glorioso, under large flat rock at base of overgrown hill (1 specimen). Same data except 24 October, 1977 (1 specimen).

The campodeids key to the genus Campodea subgenus Campodea Westwood, 1842, in Paclt (1957). Silvestri (1933a) and Paclt (1957) list two species of this subgenus occurring east of the Mississippi River, Campodea $(C$.) fragilis Meinert, 1865, and Campodea $(C$.) plusiochaeta Silvestri, 1912. Both are illustrated and described by Silvestri (1912). Our specimens more closely match C. plusiochaeta because the cercal setae are fairly long on all segments, as opposed to the long basal and shorter distal cercal setae of $C$. fragilis, and because there are bifurcate antennal setae, as opposed to the serrate or plumose setae of $C$. fragilis. Nevertheless, the determination is not firm and the specimens should be listed as Campodea (Campodea) ? plusiochaeta Silvestri, 1912. The Ohio japygids key in Paclt (1957) to the genus Metajapyx Silvestri, 1933. Using Smith and Bolton (1964) they key to Metajapyx subterraneus (Packard, 1874) 
which is recorded from Ohio, Pennsylvania, Kentucky, Virginia, and District of Columbia. It is the only species recorded from Ohio; our Franklin County specimens constitute a new northern-most record in the state, and are one of the very few American records of the genus in glaciated territory. The Alabama japygid keys (in Paclt, 1957, and Smith and Bolton, 1964) directly to Metajapyx steevesi Smith and Bolton, 1964, known from Mississippi, Alabama, Georgia, South Carolina, North Carolina, Tennessee, and Virginia. Our record is especially noteworthy because it marks the southernmost limits of both the species and the genus in North America.

\section{RESULTS}

CLEANING. Involves grooming with the mouthparts.

Antenna Clean. Passage of the antenna through the mouth is accomplished in two major modes: unassisted and assisted. In unassisted, which is the usual mode in Diplura, the antenna deflects into the mouth due to its intrinsic musculature, and the legs are not involved. In Campodea this movement is vertical to the substrate, the antenna is curled ventrally under the head and is chewed by the mouthparts; in japygids the movement is rarely vertical, the antenna usually is curled along a more horizontal plane from an initial position lateral of the head, and is usually drawn rapidly through the open mouthparts; less frequently it is chewed by the maxillae. In the much rarer assisted mode, the ipsilateral foreleg pulls the antenna into the mouth and in both families is either returned to the substrate or held in mid-air; in addition, the japygids were occasionally observed using the ipsilateral foreleg to help hold the antenna in the mouth by placing the leg crosswise in front of the mouthparts. Pagés (1967) points out that in Dipljapyx the foreleg holds the antenna during chewing by the maxillae, but is not used when the antenna is drawn through the maxillae without chewing movements.

Palp Clean. A maxillary palp is passed unassisted through the mouthparts in the anterior mode in which the palp tip projects posteriad and is drawn anteriad out of the mouth. This was observed clearly in Metajapyx. (In Campodea, maxillary palpi are one segmented and the labial palpi are vestigial.)

Foreleg Clean. A foreleg is raised and extended forward while the head turns to the side to reach it; the leg is essentially in a ventrolateral position during cleaning, and is drawn posteriorly through 
the mouth, tarsal claws last. This occurs in both families and all three genera.

Midleg Clean. A midleg is brought forward alongside the body and the head turns and dips to reach it, the limb moving posteriorly through the mouth, tarsal claws last. There are three modes: under $L_{1}$, in which the foreleg is raised out of the way, in both families; $L_{1}$ pull, in which the raised foreleg is used to pull the midleg into the mouth, seen rarely in Campodea and reported in Dipljapyx by Pagés (1967); and over $L_{1}$, where the foreleg remains on the substrate and the midleg crosses above is, seen in Metajapyx.

Hindleg Clean. A hindleg is brought forward alongside the laterally arched body and the head turns and dips to reach it, the limb moving posteriorly through the mouth, tarsal claws last. There are three modes in Diplura: under $L_{1+2}$, where fore and mid legs are raised out of the way, in both families; under $L_{1}$, over $L_{2}$, which is self-explanatory and occurs in both families (in this mode both families usually raise and partly extend $\mathrm{L}_{1}$, and japygids sometimes flex $\mathrm{L}_{1}$ and position it under the body); and $L_{1}$ pull, in which the foreleg helps pull the hindleg to the mouth, in Campodea and Dipljapyx.

Fore-Midleg Clean. Ipsilateral fore and midlegs are passed simultaneously through the mouth in anterior-posterior sequence. This infrequent action occurs in both Campodea and Metajapyx. Sometimes both tarsi are involved, but usually the fore tarsus and mid tibia are the parts cleaned.

Fore-Hindleg Clean. As above, the ipsilateral limbs moving posteriorly through the mouthparts, observed rarely in Campodea.

Mid-Hindleg Clean. As above, except that the movement seems to be a rare continuation of Hindleg Clean, under $L_{1+2}$, where the midleg becomes involved; in no case was the movement initiated independently of Hindleg Clean. This movement was observed rarely in Metajapyx.

Body Clean. Both families can bend double and use their mouthparts to groom body surfaces from the thorax to the cerci. These movements are less frequent than other grooming, so it is not known if the differences between the two families are real or sampling error. Watching these animals, the observer rapidly gets the impression that they can probably reach any body part they wish except the pronotum. At present, the campodeids have been seen cleaning all three coxae with the head directed ventro-posteriad; 
they also clean the lateral edge of the body, the styli, and the cerci with the body curled laterally. Cercal grooming techniques appear to be very diverse and are more controlled by position and substrate irregularities than by a stereotyped program. For example, the cerci can be held by $L_{1}$, or by $L_{1+1}$, or by $L_{1+2}$, in each case the remaining ipsilateral legs are under the cercus; other variants involve $\mathrm{L}_{3}$ raised out of the way, $\mathrm{L}_{2}$ raised out of the way, and the cercus positioned over all three ipsilateral legs. Body cleaning in japygids extends at least from the mesonotum or mesosternum to the cerci, including dorsal, lateral, and ventral surfaces; during cercal grooming, the mouth can work the outer margin of a forceps from base to apex, around the tip, then the inner margin to and across the anal area, and out the inner margin of the contralateral forceps to its tip; the far outer margin is not groomed until the insect straightens and bends to the opposite side. In Dipljapyx Pagés (1967) reports that the thoracic legs hold the abdomen when the body is tightly curved to clean from the mesothorax to the fifth abdominal segment.

RUBBING. Involves progressive contact of body parts with each other or with the substrate. In Diplura, all rubbing is of low frequency.

Antenna-Foreleg Rub. The fore tarsus or tibia is used to rub the dorsal surface of the ipsilateral antenna. This occurs in Campodea where the movement is confined to the basal antennal segments, and is sometimes combined with and precedes Antenna Clean, assisted.

Head-Foreleg Rub. In Campodea, the fore tarsus is used to rub the venter of the head and the mouthparts; in Dipljapyx, Pagés describes head capsule rubs but does not indicate the areas involved.

Head-Midleg Rub. Also in Campodea, a midleg is used to rub the venter of the head.

Head-Substrate Rub. Dipljapyx was observed rubbing the labial region of the head on the substrate with a sideways motion.

Body-Midleg Rub. In Metajapyx, the midleg is used to rub the dorsal and lateral surfaces of the thorax.

Body-Midleg-Midleg Rub. Also in Metajapyx, this is the bilateral version of the previous movement, both midlegs rubbing different thoracic regions simultaneously.

Body-Hindleg Rub. In Metajapyx, the hindleg is occasionally used to rub the dorsal or lateral surfaces of the thorax. Body Rubs can be combined, for on one occasion the thorax was rubbed 
simultaneously by a mid and hind leg from opposite sides.

Body-Substrate Rub. Pagés (1967) reports that Dipljapyx rubs the thoracic sternum and abdominal base energetically on the substrate. He recognizes that this may be territorial marking, but believes that grooming is more probable.

\section{DisCUSSION}

The grooming patterns of Campodeidae and Japygidae are basically similar with one major exception. In Antenna Clean, campodeids chew the antenna with the maxillae during passage through the mouth, while japygids usually open the mandibles and then scrape the antenna rapidly through the open maxillae without chewing motions. Japygids can also chew the antenna but do so less frequently. The differences in grooming suggest different maxillary structures. Dissection of Metajapyx reveals an extraordinarily complex lacinia with five pectinate lamellae along the mesal face. Since we believe that these lamellae are the structures with which the antennae are cleaned; their distribution and function should be considered in future dipluran studies. Illustrations of these structures can be seen in the following works.

Japygidae: (note that the last genus is sometimes listed in a separate farnily).

Indjapyx crivellari (Silvestri) as Parindjapyx (Silvestri, 1932, fig. XXXI, 4).

Burmjapyx major (Grassi) as Japyx (Silvestri, 1922, fig. IV).

Metajapyx confectus Silvestri (Silvestri, 1947, fig. 2).

Monojapyx simplex profusa Silvestri as Japyx (Silvestri, 1932, fig. XXI, 2).

Catajapyx confusus (Silvestri) as Japyx (Silvestri, 1929, fig. 2-5).

Heterojapyx gallardi Tillyard (Snodgrass, 1935, fig. 79).

Evalljapyx hubbardi (Cook) as E. sonoranus (Silvestri, 1947, fig. 3).

Parajapyx isabellae (Grassi) (Paclt, 1957, fig. 37).

Anajapygidae:

Anajapyx vesciculosus Silvestri (Silvestri, 1905, fig. 4).

Anajapyx hermosus Smith (Smith, 1960, fig. 9).

Projapygidae:

Symphylurinus stangei Smith (Smith, 1960, fig. 7). 
The general localities of these twelve species are, in sequence: Is. Rhodes; Mediterranean; Washington, D.C.; Greece; Greece; Australia; se. Arizona; semi-cosmopolitan; Italy; California; Mexico; Mexico.

The remaining two families of Diplura: Procampodeidae and Campodeidae are described by Paclt $(1957$, p. 5) as having tonguelike processes ("languettes") on the lacinia, but lacking pectinate lamellae, while Smith (1960) simply states that the two campodeiform families are without "pectens". In Procampodea the lacinial apex has a mesal row of 4 projections, one of which is bifid; these structures are illustrated by Silvestri (1905b: pl. XII, fig. 21). The functional morphology of dipluran mouthparts is further complicated by another feature: the presence of an antebasal serrate prostheca (sometimes called a "lacinia mobilis") on the mandibles of campodeids (see Paclt, 1957, fig. 7), anajapygids and projapygids (see Smith, 1960, figs. 10, 13 respectively), and anteapically on procampodeids (see Silvestri, 1905b, pl. XII, fig. 19, 20). The functions of these maxillary and mandibular structures have not been demonstrated, but based on our observations, grooming is one of the most probable uses of the pectinate lamellae.

Jander (1966-842) states that grooming ". . . the antennae and all of the legs with the mouthparts ... is . . to be regarded as the primordial mode of grooming..." in tracheate arthropods. It is true that oral cleaning movements predominate in diversity and frequency in primitive taxa, but it is also true that virtually all primitive arthropods have rubbing movements too. In most cases it is impossible to decide objectively which came first.

Many factors affect grooming, and all act on both primitive and derivative taxa. For example, grooming movements have constraints imposed by body flexibility and degree of leg movement. The configuration of a coxa and its cavity can be primitive or derivative, but superimposed on this basic structure are the results of selection for plane of leg movement, rotation, strength, speed, body height, and grooming requirements. The resolution of these diverse pressures must result in a morphological compromise which affects grooming capability, but has little to do with primitiveness. Additional examples are numerous. An elongate, flexible, softbodied organism has different grooming patterns from a fatter, more rigid, sclerotized organism; one with easily abraded scales will 
be different from one with firm setae; and an interstitial inhabitant will be different from a subcortical or leaf-litter inhabitant. The point is that all of these kinds of organisms occur in Apterygota and all are among the most primitive known hexapods.

In Diplura, grooming of the antennae, mid- and hindlegs involves at least fourteen cleaning positions, all of which appear to be satisfactory. This diversity is quite remarkable and is unequaled in other insects (Valentine, unpubl.). The grooming of dipluran forelegs involves only one mode. The stereotypy of foreleg grooming contrasts sharply with the diversity of antennal, mid- and hindleg grooming. The logical explanation is that the single foreleg technique works in most or all situations, while no one technique works for the other appendages. Environmental constraints appear to require that the insect reach and groom its antennae, mid- and hindlegs in several alternate ways. Diplura are basically interstitial organisms. Almost all specimens were found in the soil under undisturbed stones or boards, or in soil clods in gardens. A standard technique for finding campodeids was to break up the damp clods in a freshly plowed field or while digging potatoes. The very fine tunnels and cracks in this unyielding substrate are inhabited principally by small myriapods, Collembola, and Diplura. Since campodeids do not burrow and japygids do so very weakly (Pagés, 1967), they primarily use the interstices already present. In such a habitat body configurations are subject to an infinite diversity of living spaces. A grooming behavior possible in one crack may be impossible in another; however, a modification may work. We believe that the unequal grooming diversity in Diplura is a response to the problems of an interstitial life style. Foreleg grooming, where the leg is simply raised to the mouth, does not require any special bending or movement, so one technique does the job. Antennal, mid- and hindleg grooming require unusual movements of the appendage or of the body. Such movernents may be limited by the varied configurations of the crawl space, and must accommodate to those configurations; thus, a variety of alternate positions appears to be a necessity.

It is important to contrast the remarkable freedom of grooming positions of Diplura, with the very high degree of stereotypy in such orders as Diptera and Hymenoptera. The point is that a discussion of insect grooming based on Diptera or Hymenoptera is as biased towards stereotypy as a discussion of Diplura is biased towards lack 
of stereotypy. Present literature emphasizes the stereotyped aspects of grooming, but it should be obvious that generalizations based on highly derivative or primitive orders are not valid for the entire class and may be skewed in opposite directions. The order Thysanura would be a heuristic study because of the diversity of surface textures. There are scaly lepismatids, campodeid-like nicoletiids, and sclerotized, non-scaly lepidotrichids. Grooming in these three families may further clarify why the degree of stereotypy varies from taxon to taxon.

\section{Literature Cited}

FARISH, D. J.

1972. The evolutionary implications of qualitative variation in the grooming behavior of the Hymenoptera (Insecta). Anim. Behav., 20: 662-676, fig. $1-2$, tab. I-III.

Hlavac, T. F.

1975. Grooming systems of insects: structure, mechanics. Ann. Ent. Soc. Amer., 68(5): 823-826, fig. 1-2.

JANDER, URSULA.

1966. Untersuchungen zur Stammesgeschichte von Putzbewegungen von Tracheaten. Zeitschr. Tierpsychol., 23(7): 799-844, fig. 1-21, tab. 1-4.

LIPPS, K. L.

1973. Comparative cleaning behavior in Drosophila. Ph.D. Dissertation, University of California, Davis.

PAClT, JiŔí.

1957. Diplura. In Wytsman, Genera Insectorum, fasc. 212: 1-23, fig. 1-37, tab. 1.

Pagés, Jean.

1951. Contribution à la connaissance des Diploures, Bull. Sci. Bourgogne, 13: Suppl. mecan. 9: 1-97, fig. 1-149.

1967. Données sur la Biologie de Dipljapyx humberti (Grassi). Rev. Ecol. Biol. Sol, 4(2): 187-281, fig. 1-26, tab. 1-15.

Silvestri, FilipPo.

1905a. Nuova contribuzione alla conoscenza dell'Anajapyx vesciculosus Silv. (Thysanura). Annali della R. Scuola Superiore d'Agricultura in Portici, 6: 1-15, fig. 1-12.

1905b. Materiali per lo studio dei Tisanuri VII. Dexcrizione di un nuovo genere di Carnpodeidae del'Italia meridionale. Redia, 2: 115-119, 120, pl. XII.

1912. Contribuzione alla conoscenza dei Campodeidae (Thysanura) d'Europa. Bollettino del Laboratorio di Zoolegia Generale e Agraria della R. Scuola Superiore d'Agricultura in Portici, 6: 110-147, fig. I-XXXI.

1929. Zoologische Forschungsreise nach den Jonischen Inseln und dem Peloponnes von Max Beier, Wien III. Teil Japygidae (Thysanura). Sitzungsberichte d. mathem-naturw. Klasse Acad. Wissensch. Wien, Abt. I, 138(9-10): 457-461, fig. 1-4. 
1932. Nuovi contributi alla conoscenza della fauna delle isole Italiane dellEgeo II. Thysanura-Entotropha (Insecta). Bollettino del Laboratorio di Zoologia Generale e Agraria del R. Instituto Superiore Agrario in Portici, 27: 61-111, fig. I-XLIV.

1933a. Quarto contributo alla conoscenza dei Campodeidae (Thysanura) del Nord America. Ibid 27: 156-204, fig. I-XXXII.

1933b. Sulle appendici del Capo degli "Japygidae" (Thysanura Entotropha) e rispettivo confronto con quelle dei Chilopodi, dei Diplopodi e dei Crostacei. Ve Congrès Internatl. Entom., Paris, 1932: 329-343, fig. I-VII.

1947. On some Japygidae in the Museum of Comparative Zoology (Dicellura). SMITH, L. M. Psyche, 54(4): 209-229, pl. 17-19, text-fig. 1-6.

1960. The family Projapygidae and Anajapygidae (Diplura) in North America. Ann. Ent. Soc. Amer., 53: 575-583, fig. 1-25, tab. 1.

SMith, L. M. AND C. L. Bolton.

1964. Japygidae of North America 9. The genus Metajapyx. J. Kansas Ent. Soc., 37(2): 126-138, fig. 1-10.

SNODGRASS, R. E.

1935. Principles of Insect Morphology. McGraw-Hill Book Company, Inc., New York and London, ix + 667, fig. 1-319.

VAlentine, B. D.

1973. Grooming behavior in Coleoptera. The Coleopterists Bulletin, 27(2): 63-73. 

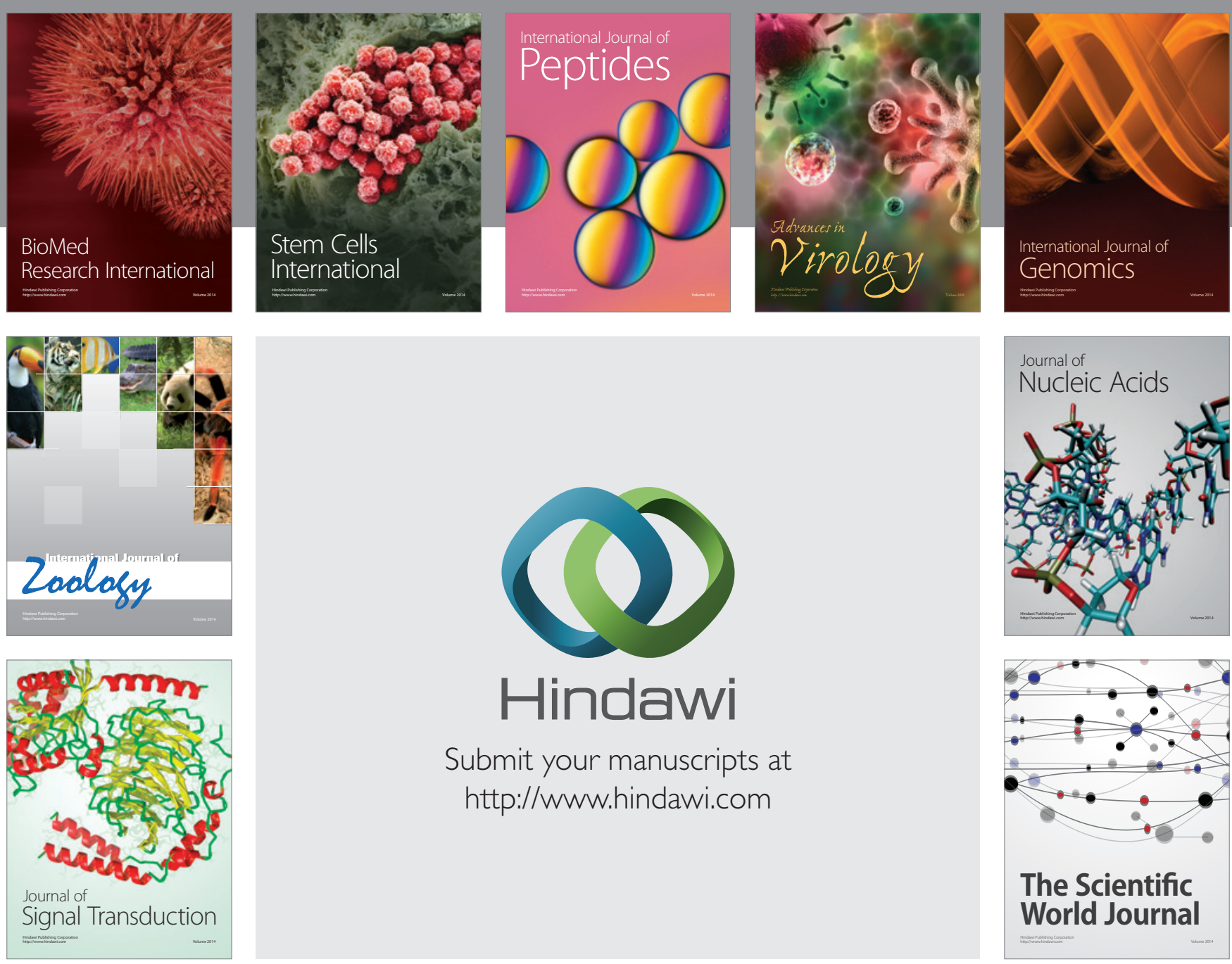

Submit your manuscripts at

http://www.hindawi.com
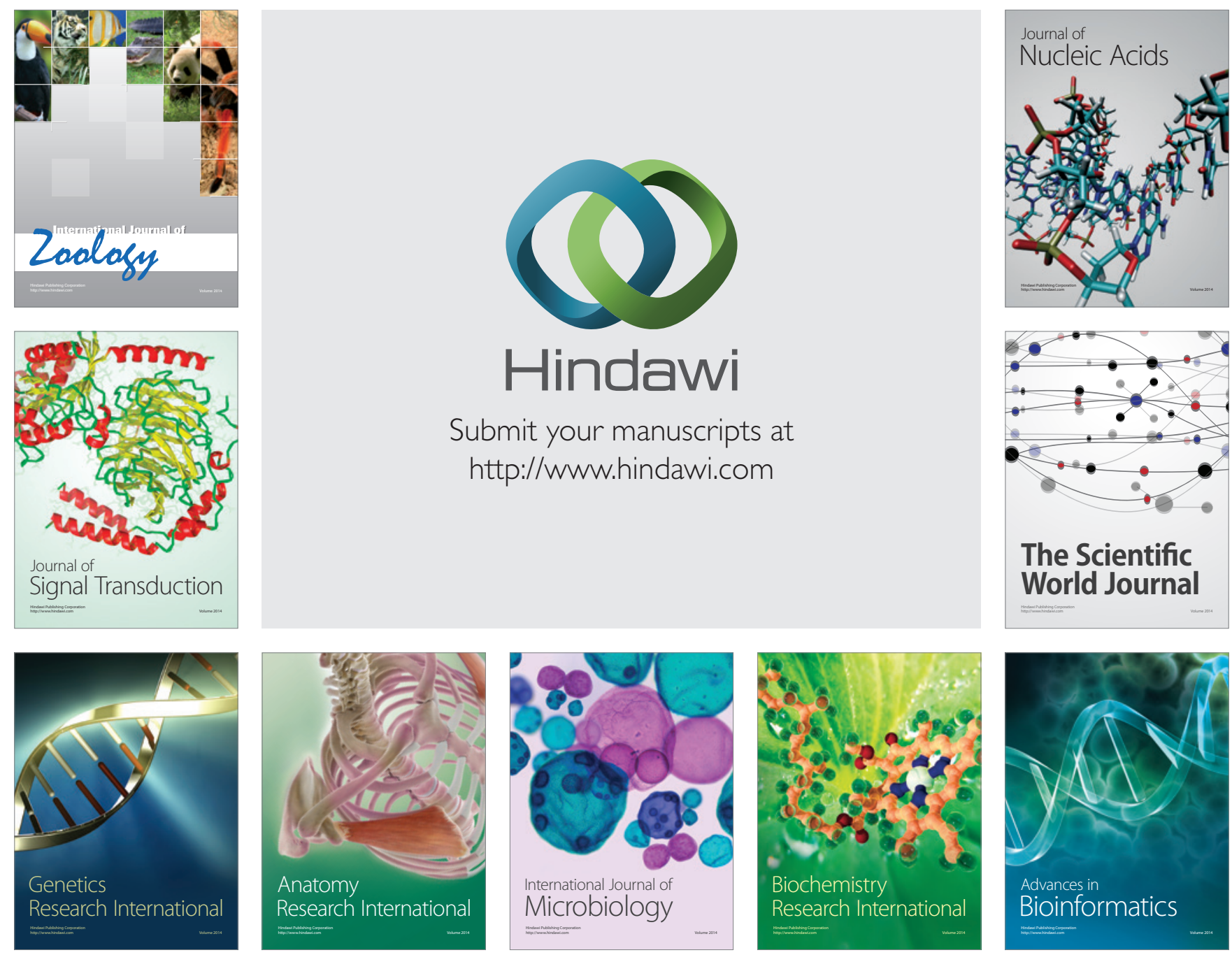

The Scientific World Journal
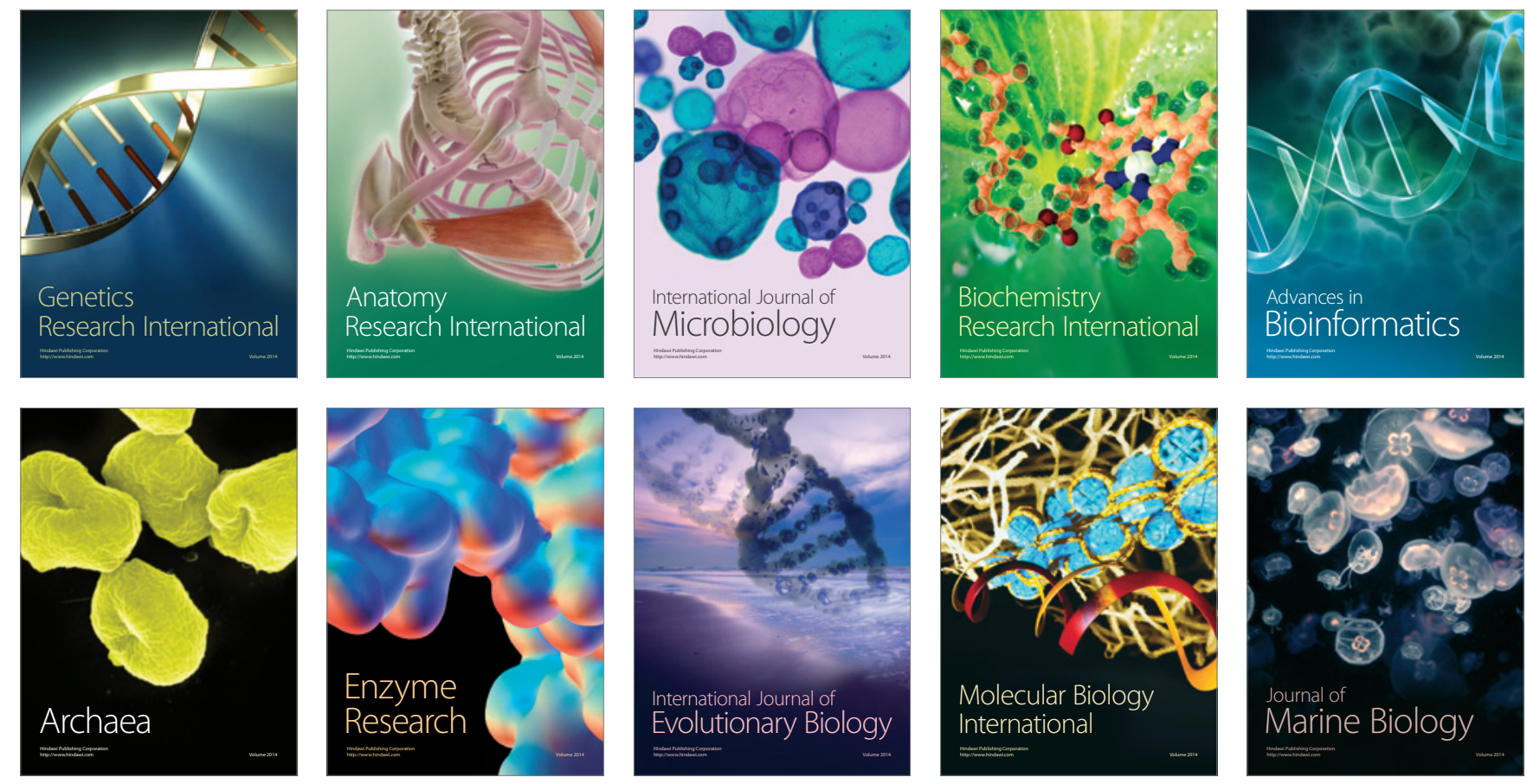